\title{
TEACHERS AND TEACHING.
}

\author{
PRESIDENT'S ADDRESS.
}

\author{
By A. W. Thornton, L. D.S., D.D.S., D.D.SC, Montreal.
}

(Read before the American Institute of Dental Teachers at Atlanta, Georgia.)

$\mathrm{I}^{\mathrm{P}}$ F I UNDERSTAND aright the Genesis of this organization, its first aim was to create a kind of clearing house for the exchange of ideas concerning certain technical operations pertaining to the Profession of Dentistry, with the twofold object of developing a high standard of technical efficiency and establishing this higher standard in as many of our schools and colleges as possible. The object was a worthy one, and I imagine that no one will question the fact that this two-fold aim has to a very great extent been accomplished. The achievements of American Dentists and American Dentistry along technical lines have been almost universally recognized. But in process of time, a broader field was entered upon and pedagogy and pedagogics gave scope to imagination and an opportunity to discuss everything, from the pronunciation of the name of the Society, to the perfection of a four year curriculum.

In recent years, we have had presidential addresses dealing with such subjects as:

1. Post-graduate Teaching.

2. The Relation of the Teaching to the Examining Body.

3. The Four Year Curriculum.

All these things are important, very important, but as "the greatest study of mankind is man", so it has appeared to me. A short time might be advantageously spent on the two most important factors of a teachers' institute, viz: The teachers themselves and the work in which they are engaged.

Let me ask a very simple question: "Why are you men here?" Because you are good Dentists? No. Because you know Dental Anatomy or Dental Histology or Dental Pathology or Dental Prothesis? No. You are here because you are teachers. So far as this Institute is concerned, that is your only excuse for being here. Let me ask another simple question: "How many of you would want on your Faculty, a Professor of Prosthetic Dentistry who had never read a book on the subject, or a Professor of Bacteriology who had never stained a slide nor seen a pathogenic organism thru a microscope?" And yet I fear, that on some of our Faculties we have men who have never read a book on Teaching or taken any instruction at an institute where students are taught to teach. So far as this Institute is concerned the business of the members is "Teaching" and we should strive to know as much as possible of the work which we undertake.

What is a Teacher? The answer of course is easy. "A Teacher is one whose business it is to teach." But what does "to teach" mean? "To teach" is to "instruct", "to cause to know." So then, a teacher is one who causes another person to know something, that the other person did not previously know. So the word 
Teacher implies two persons, the teacher and the learner. The amount which any one of us teach is measured absolutely by the amount which the other person learns.

If some day you are curious to know just what a lecture period has actually accomplished, stop the lecture ten minutes early, have the students close their note-books, then ask some member just to tell in his own words what he has learned from the lecture. The result of such an experiment might possibly surprise some of us. Just here, let me draw attention to a statement frequently heard when a question is asked, "Oh, I know alright but I can't explain it." Do not be deceived by any such statement. No one knows any subject or any fact as it should be known, until such person is able to tell about it.

Most thoughtful teachers are convinced that no student can make knowledge his own without an effort, cannot add to the sum total of his store of knowledge by mere hearing. Most of the experienced teachers know, because of their experience, that no student knows a subject until in some way he is able to reproduce it, by telling of it, by writing it, by shaping or fashioning it in some manner which demonstrates that the subject has been woven into his intelligence, has become a definite part of his mental equipment.

With this thought before us: that teaching implies at least two persons, a teacher and a learner: these two persons interested for the time being in the same subject, and that at the end of the lesson or lecture period, the learner has made his own some knowledge that he did not previously possess, let us ask how is the attainment of this object usually attempted?

1. By purely didactic effort, i. e. a teacher talking on some subject for an hour, more or less. But we must always bear in mind that "talking" is not "teaching."

2. By assigning a lesson and conducting a "quiz" on a lesson, presupposing that all members have studied the assigned lesson.

3. By taking a text-book, reading a paragraph or page to a class and then trying to explain to the class what the author meant.

4. By throwing pictures on a screen with a projecting lantern and trying to explain the pictures, etc.

5. By combinations of any or all of these methods.

Any of these methods may be used to advantage. But to use the same method for every subject and every lecture period, is nothing less than a crime. The man who reads an hour's essay every time he enters a class room and imagines that he is "teaching" has still much to learn. It will not be very long until typewritten copies of these lectures are for sale and then, attendance at lectures is for the sole purpose of having attendance recorded. This is a lazy man's method.

In many of our college announcements, much is made of the fact that frequent quizes are conducted. A "quiz" as I understand the term, may be a good teaching exercise or it may be the variest waste of time. If by a "quiz" we mean a discussion between students and teachers of a subject, with the object of making clear and distinct the student's knowledge of that subject, which perhaps up till that time he has not been able to completely master, all well and good: or if it is conducted with the object of correcting any false ideas that may have been gathered from a previous lecture, a "quiz" may be a valuable teaching method. But if by a quiz, you have in mind a kind of catechetical exercise in which a teacher propounds 
certain questions from a quiz compendium and the students answer these questions, having learned the answers out of a book used by the teacher or some "key" to the book of questions, such teaching in my opinion is an insult to a student's intelligence.

Dr. Thomas Arnold was perhaps the greatest teacher that Britain ever produced. By this I mean that he exerted a greater influence on the intellectual and moral life of Britain, than any other individual teacher in the Empire. Dean Stanley says of the teaching method of Dr. Arnold, "His whole method was founded on the principle of awakening the intellect of every individual boy." I want to ask some of you men here, how much intellect was awakened by some of your "quiz" masters whose exercises were begun, carried on and finished within the confines of a quiz compendium?

The use of a text-book by a teacher in a lecture room is a practice that certainly should not be encouraged. Students do not come to a lecture room to hear a teacher read from a book, which in all probability they themselves possess, nor to look at pictures on a screen which they can study to better advantage from the text book during home study. Textbooks the teacher must have, but only for preparation. A man, to teach any subject, must read everything possible on his subject and think and select and strive to illustrate and then saturated with his subject, come to the class and in simple direct language, give to the class the well assimilated material which in very truth has become his own. Listening to such a man teach, students forget for the time being that he is simply a medium of communication; to them, he is the very fountain of knowledge.

In a book on Teaching and Teachers, which I read a short time ago, I came across this significant sentence, "It is folly to endeavor to make ourselves shine, before we are luminous."

Just a word about the use of a lantern in teaching. Occasionally for some special subject, a lantern slide projected onto a screen may be a valuable aid in teaching. But the almost universal knowledge of photography and the easy production of lantern slides has made the use of the lantern a very easy method of filling in a lecture period with a hybrid production: a kind of cross between a scientific essay and a cheap movie. Whenever you use a lantern in your lecture, you lose some of the great essentials of a well taught lesson. Because the room is in darkness, discipline is to a very great extent lost, the teacher becomes a voice only, the student loses the enthusiasm of the techer's presence, the teacher's face, the teacher's eye: while the teacher loses the inspiration which comes from the fixed gaze, the attentive bearing or possibly sometimes, the look of doubting incredulity which is so often observed, first on one face, then on another, in an interested class.

Notwithstanding anything I have said concerning "methods" of teaching, we must never lose sight of the fact that the method is always subordinate to the man.

A teacher influences more by what he is six days of the week than by what he says in one or two hours of the week. In view of the plasticity of the material with which we are dealing, how careful we should be of the impressions which we make.

I have the most profound respect for the men who constitute the membership of this Institute. To an extent, perhaps not fully recognized, the tremendous change which has come over the profession of dentistry in the past twenty-five years has been brought about very largely by this body. In view of the herculean tasks still to be accomplished, how essential it is that something more than adeptness in technic or brilliancy 
of intellect should characterize the men who are filling the ranks of our faculties.

A young man of very ordinary ability but of good morals and with a vision of what he is called to do, may by study, by training, by careful oversight, develop all the qualities necessary to become a successful teacher. But a man of loose morals, of unclean mind, of filthy tongue in any school, is a center of pestilential infection, and such men are usually of that class from which little improvement may be expected, as they are usually thoroly satisfied with their own superior wisdom.

Regardless of the method or methods which you may adopt, there are some things which cannot be left out of the account by any man who calls himself a teacher.

First, there is preparation. By this I do not mean that a man writes a series of lectures on a subject, has them typewritten, numbered, $1,2,3$, 4, etc., and then uses these until they are yellow with age, dog-eared with use and "holey" where they are folded. No. By preparation, I mean reading and thinking, gathering and sifting, illustrating and changing, until "The best you can do will be the worst you will do."

To be a teacher is to be a student: to be a student is to lead a life of selfdenial: it means giving, not getting: it means in most cases to be underpaid for the time and labor spent-but-if you have a vision, it means to inspire those whom you teach: to live again in the lives of the men who go out from our schools: and it is worth while.

It is necessary to know what to teach as well as how to teach. Teach principles, not trivial, wearisome details. Let me give you an illustration of what I mean by this. I listened once to a man give a lecture on condensed gold fillings. He described everything from shaking hands with the patient, to the final touches of the toilet of his cavity. Then he said, "I would put the first pellet in at this point, the second pellet here, the third here, and the fourth here, pointing out the location of each pellet on a large drawing of a prepared cavity. Going on, he said, "I would put the fifth pellet here: then he stopped, considered, looked thoughtful: and turning to the audience (a convention of dentists, by the way,) he said, "No, I wouldn't put the fifth pellet there, I would put it here" (indicating a point about a $M$. M. from the first location). Of course it was "Camouflage" pure and simple. He forgot the "principle" in his attempt at exactness: his high explosive was "dud."

There is an old saying that "Honesty is the best policy." In teaching, "honesty" is not a policy as that word is usually understood, honesty is a cardinal principle. Do not attempt to teach what you do not know nor to explain technical operations which you are not prepared to demonstrate. To explain: In one of our colleges, there was a Demonstrator. Complaint was made by the students that this particular Demonstrator did not demonstrate: he talked about how things should be done or were done, but never did these things himself for the students. When he was spoken to by the head of the department, he acknowledged very frankly that what the students said was true. The reason he gave for this "refusal to demonstrate," for he persisted in his refusal, was, that he might make a failure of a demonstration or he might have an accident, and he could not afford to "fall down" before the students. I need hardly say that such a man should have no place on a teaching staff. He failed to realize that his failure, if he had one, might be used to draw attention to some faulty step in technic or that his accident might be used to show a method of repair. What that demonstrator did accomplish most perfectly was that he lost the confidence and respect of the 
entire class. Just a few words about the party of the second part, "the learner."

When all is said and done, the success or failure of our teachers and teaching, the right of our schools and colleges to exist and carry on their work, must be determined by the finished product of these institutions, the graduates. A number of questions have arisen during the past few years, in connection with our work, and all thoughtful men recognize that the present is a momentous, transitional, psychological period in the evolution of our professional status. Is dentistry a specialty of medicine? Should a man, before being given a license to practice dentistry, be compelled to possess a degree in medicine? Should the course in medicine be so arranged that a man would be able to obtain a degree both in medicine and dentistry in five years, and should this standard be adopted by all our dental schools?

These questions are continually coming to the surface, and I believe that this Teachers' Institute must be the court of final appeal in settling these matters. And in this settlement, a review, a close study of the past must of necessity be a potent factor in determining the conditions of the future. Let us here and now ask ourselves honestly: are we satisfied with present conditions? Are we proud of the men who graduate from our colleges, of the service which they render to the public, of the estimation in which they are held by the public. In a journal of recent date, there was an article dealing with the history of dentistry during the last fifty years. These two sentences are taken from that article: "We had no Dental Laws but Dental Ethics were patterned after the Ethics of the Medical Profession and we believe were more strictly conformed to in general than at the present era. We had not the advertising dentist whose attractive card of self-praise, and scab work prices and misleading promises appear in the Sunday newspapers."

Now, I know full well that the advertising dentist is only a sort of malignant growth on the professional body but unfortunately it is often so much in evidence that it is the only part that a large portion of the public sees.

In a recent encounter with a decent advertising agency, I was surprised to learn that reputable business men could see no reason why dentists should not advertise just as any patent medicine vendor or a departmental store manager advertises his wares, in the most seductive manner possible. In a splendid address given at one of the Sectional meetings in Pittsburgh last year, this striking sentence was used, "The curse of dentistry has been the dollar Amalgam filling." In the same address, this significant question was asked, "What percentage of dentists do good work?" The essayist's reply was, "I do not believe twenty per cent. do-one in five."

What is the significance of these statements coming from one of our most thoughtful and conscientious teachers? Is it not this that many of our graduates leave our schools, lacking absolutely any conception of the fact that dentistry is in any way associated with preventable disease, lacking a vision of dentistry as an important factor in the physical, mental and moral welfare and happiness of the community? Let me quote one paragraph farther, from that address of last year:

"We have made wonderful progress in the last twenty-five years but what is the trouble with this distressing four out of five which has been mentioned? They left college with high ideals, certainly the great majority of them. Why did they fall by the wayside? We taught them how to do the work of dentistry as we know it each year but we did not teach them how to defend themselves and 
how to grow, hence the public in general receives poor dentistry and dentistry in general is rated low socially, intellectually and financially."

The picture presented is not a cheerful one and while all may not be ready to endure these statements in their entirety, all must admit that there is much cause for deep reflection. A great responsibility rests upon the men who year after year come together as members of this Institute. Upon you and the schools which you represent must devolve the task of giving to dentistry the place which it should occupy.

An attempt is being made now, to classify all schools as first rate, second rate, third rate, etc. But it must be borne in mind always, that in any such classification there is an element, a force, an asset; that cannot be weighed nor measured, nor tabulated nor appraised. The influence of the teacher, the educational and cultural atmosphere created, the moral standards established, these are the things of greater worth than the financial value of the equipment or the architectural beauty of the building in which the teaching is done.

In a book by Sir William Osler, (which I should advise every man to read,) entitled "Counsels and Ideals," this paragraph occurs:

"The great possession of any University is its great names. It is not the 'pride, the pomp and circumstance' of an institution which bring honor, nor its wealth, nor the number of its schools; nor its students who throng its halls, but the men who have trodden in its service, the thorny road thru toil, even thru hate, to the serene abode of Fame, climbing "like the stars to their appointed height."

In conclusion, let me pay a debt which I owe to the members of this body. Sixteen or seventeen years ago, you were kind enough to receive me "one of the least of all the disciples." The things which I have learned from you form the greatest part of my poor fund of knowledge, my association with you in our annual gatherings has been among the happiest experiences of my life, the friendships which I have formed have made me rich, in the things that abide: and for all these, a debt which I can never repay.

\section{Discussion.}

\section{Herbert L. Wheeler, New York.}

The excellency of this paper is such that a discussion of it must be merely an endorsement of the many points brought out by our President. I am so in accord with the views expressed therein that I can but amplify and dwell upon the details of what has already been said.

The statement concerning the reading of an hour's essay every time the teacher enters the class-room, is, I think, extremely easy to prove. Observation has shown me that what is said about the typewritten copies of this kind of lecture is accurate and correct. I might say that this situation oftimes leads to still a worse evil, which is that the professor is persuaded to make copies of these lectures himself and sell them to the students at considerable profit, so that in many cases the student is deterred from buying the textbooks which he so sadly needs. I speak from knowledge and not as a theory when I say that that is a crying evil in some institutions.

As to the use of the quiz, if the quizmaster has a thoro knowledge of his subject ( $\mathrm{I}$ use an if there) in teaching, there may be a difference of opinion as to its value. One thing is certain: Utilized regularly and with discretion it certainly helps a student to memorize the subject, and after all the effect we desire to produce upon the learner is that of enabling him to remember the subject sufficiently in detail to permit of his having it at hand when the necessity for its practical use develops. 
I endorse fully the advice to read everything obtainable upon the subject one desires to teach. It would seem, however, that ability to teach well requires considerably more than this. One may read ad libitum or more and yet fail to acquire the necessary qualities of a teacher. To teach well, lucidly and understandingly, it is imperative that one have a thoro and well-grounded knowledge of the subject. A thoro knowledge of dental subjects cannot be secured by reading alone. Reading must be supplemented by actual observation and experience. One cause of weakness in both medical and dental teaching today is that so many teachers are made of men who lack practical experience, either because of their youth or lack of opportunity.

As a general proposition the statement regarding the use of the lantern and the teaching in darkness is correct At times, however, this method has very great advantages, and its reasonable use should not be entirely eliminated. I think with the author that one's ability to teach is quite as much to be measured by the personality of the individual, if the necessary knowledge of the facts is there, as by the careful reading of a lecture or an essay. It should not be forgotten that teaching is not entirely. by word of mouth. The learner ofttimes gets as much by observing the actions, habits and mode of speech, as from one's use of language. Hence a good teacher will consider all the little proprieties in manners and methods of speech and also preserve a correct moral attitude.

As to the teaching of ethics, that is extremely necessary, but it is more desirable that the teacher live the ethics if he expects the student to profit along this line.

Aside from the teaching of sound economic principles, I do not think the question of dental fees enters into the teaching of dentistry:
It is true that an institution's reputation and standing is much more dependent upon the quality and ability of its teachers than upon its wealth and equipment. Fortunately, endowments cannot change this; they can only enable an institution to obtain a better teaching force. To be a good teacher requires discrimination and judgment. I believe these can only be obtained in the highest degree by experience. It is quite as essential that a teacher refrain from presenting to immature minds the uncertain and unproved, as that they discard the obsolete and outworn. On this point is where the line may be drawn between a good teacher and a mediocre one. Probably no one reaches perfection in teaching, but a teacher who cannot measure up to at least sixty per cent good is hardly desirable as an example to the untrained minds in the class-room. A teacher, to be valuable to an institution, should bring reputation to the institution, and not the place reputation to the teacher.

\section{Henry W. Morgan, Nashville.}

Some ten days ago I had the courtesy of a copy of the address that you have listened to this morning and have read it over several times. It is impossible in the short time allotted for discussion to do more than to here and there endorse the speaker and perhaps to indulge in an occasional dissent from what he has said. The address that I read was as little like the one that you have heard, as Dr. Thornton today is like the man I met thirty years ago; why this is true will develop as I proceed.

We have heard with great pleasure the valuable address by President Thornton, made so by the fact that his rich experience in the school-room gives greater weight to the things he has said. Who has a better right to define what a teacher is than one who loves the work as he does?-one whose voice, accent 
and pleasing personality carries conviction and impresses those who hear him with the fact that back of a most alert brain and well stored mind is a great, sincere, loving heart. No one can ever make a teacher who is not in the tenderest sympathy with those he would instruct, no matter how much knowledge he may possess. Great minds with great gifts of oratory are preeminently great entertainers; but not often great teachers. They attract attention, but distract the mind, and make no permanent, last ing impression. All the truly great professional teachers of my acquaintance have been those who were in love with their work, masters of every phase of the subject, and able to communicate a knowledge of it in the simplest and most direct language, leaving the impression that there is much more to be known about it which their hearers are to get when they are better prepared to comprehend it. The interested teacher is constantly pointing out where such advanced knowledge may be'secured, giving reference to magazine articles and the names of authors whose works are of particular value and which can be read with confidence, and stating that those will be helpful in attaining a better knowledge of the subject.

I agree with the essayist that no teacher should go unprepared to the class-room, but his work should be thoroly digested and orderly arranged if he would hold the attention of his class. If his work is not orderly arranged, the data properly prepared and his subject presented in a logical sequence, his would-be pupils lose interest and fail to grasp the subject or to differentiate between those things which are trivial and those which are of most importance and upon which he lays the greatest stress. The appellation that we once so frequently heard, "schoolmaster,"-signifying that the teacher was master of his subject, that he directed his pupils in thought, conduct and into studious habits, inspiring their ambition,is just as essental in professional schools as it was of yore in the old western country school house.

The suggestion, that the student should be encouraged to repeatedly reproduce his thought in writing, is good, for many an error is discovered once he attempts to put his concept on paper.

The teacher is often mistaken in presuming upon the general information of his class, and falls into the error of "shooting over the heads" or the understanding of his pupils.

I agree with all the essayist says as to the use of the lantern and the reflectorscope. Both are valuable, but are subject to the objections urged against them by Dr. Thornton, and are often very greatly abused. In this connection the blackboard should not be forgotten, as a few lines often send home a thought when a half-hour of words would leave only a hazy impression. Models, charts and broad daylight are admirable substitutes for the lantern.

I most heartily agree with the essayist in all he has said about the teacher using a text-book in the class-room. Such use of the text-book is an evidence of ignorance as well as a reflection upon the intelligence of the class. And certainly if there are essential points that may be elaborated, the language of the teacher who looks directly into the eyes of his pupils is far more satisfactory and inspiring. A teacher speaking from his own experience does indeed then rise to the dignity of the profession and become "a fountain of knowledge."

Is dentistry a specialty of medicine? Should a man, before being given " a license to practice dentistry, be conpelled to possess a medical degree? Should a course in medicine be so arranged that a man would be able to obtain a degree in medicine and dentistry in five years, and should this standard be adopted by 
all our dental schools? asks the President in this address. We are reminded that "these questions are continually coming to the surface," and he believes that "this Institution must be the final court of appeal in settling them." If I may be permitted a few words as expressing the opinion of one of your members, my answer to one and all of them would be "No." Medicine and dentistry are both branches of the Healing Art; they are inter-related because they are resting upon the same scientific foundations and have for their work the amelioration of suffering humanity. Dentistry is a branch or specialty of surgery, to which it is even more closely related than to medicine. Surgery is always a branch of the Healing Art, but not specifically of medicine. Usage has given to the word medicine a broader significance than it deserves. The sciences upon which both dentistry and medicine are founded are the property of neither. Give your dental student the same broad knowledge in the sciences that the medical graduate gets, with the dental trend, which he would not obtain if the study of these sciences was pursued in a medical institution, and he is the equal of the man who holds the medical degree. And then all these questions are answered for once and for all. Will the dental schools do it?

\section{Truman W. Brophy, Chicago.}

I am very glad of the opportunity to say a few words on the subject of the President's address. It is just such an address as I would expect from the President.

The remarks made by Dr. Morgan are endorsed by me. I believe in the use of. models, I believe in the use, with restrictions, of lantern slides; not as a means of presenting the subject, but as a means of fixing the subject on the mind of the student after it has been duly presented in the lecture-room. In my own de- partment the treatment of the subject of tumors has been made much clearer by the use of lantern slides, and also, in a recent most beautiful presentation of the subject in Rochester, N. Y., by Dr. Bloodgood, of Johns Hopkins University, pictures illustrating the conditions which precede tumors were shown which brought out and served to fix in the minds of those who had the opportunity of seeing them something of the technicality of the development of tumors and the approved methods of procedure in their removal, to an extent which never could have been secured if simply an oral discussion of the subject had been given.

I have just one word more to say. Is dentistry a specialty of medicine? We have, to my knowledge, discussed that question for thirty years, and it is doubtful if we have reached any definite conclusion on the matter. But I do know this: One of the greatest advances that has been made in the history of medical education has come quite recently thru the influence of Drs. Pickart and Rishworth, of New Zealand. Here we have been claiming to be specialists in medicine, and some men have advocated the full medical course before graduation in dentistry, but such a course will never be generally adopted. What have these men done? New Zealand is a colony of Great Britain from which has come so much of value in medical education, in fact the profession there has in certain branches set the pace for medical education almost thruout the entire world. Thru the influence of the men whose names I have mentioned, there has been passed a law making it obligatory upon every medical student before he shall take the degree of M. D., to take on an average not less than six months in dental histology, dental anatomy, dental physiology, dental therapeutics, dental pathology, and oral surgery; and after passing that examination they may take 
the degree of M. D. and not until then. To slightly change the language of Dr. Chas. Mayo, of Rochester, Minn., I would say that now the dentist is bringing out more clearly to the medical profession dental pathology which is so important in order that disease may be more intelligently treated, the next great move in medical education in this and other countries will be to emulate the example set by the people of New Zealand.

\section{N. Broomell, Philadelphia.}

I want to say a word in favor of the use of the lantern in teaching. I have been using the lantern for a number of years for this purpose, and I think it has its place. Its place, however, is after the instructions have been given, to impress upon the mind of the student the subject by showing the illustrations. With the use of the modern lantern there is no reason why the room should be dark, because with the electric light you have plenty of illumination on the screen with some lights in the lecture-room. My idea has always been to compare the use of the lantern with the use of the microscope in the histological laboratory. If the student in Histology does not use a microscope he will never understand the subject which has been impressed upon him by reading and by lectures, but when he sees the specimen on the slide thru the microscope he then has the thing forcibly and indelibly impressed upon his mind. So I think the lantern has its place as a means of impressing finally on the mind of the student what you have told him before its use.

\section{George H. Wright, Boston.}

I am a new comer in your midst. I would like to bring a word to this body as a note in the method of teaching which I have been engaged in for the past fourteen years in connection with the Harvard University Dental School. Some fourteen years ago I was appointed on the medical teaching staff of the Harvard Medical School, in order to give instruction to the third and fourth year medical men in subjects related to dentistry and the diseases of the nose and throat, in connection with diseases found in the mouth. It was necessary to presuppose that these men had had no special instruction in dental anatomy, dental histology, or dental embryology. Therefore I gave them a review of the anatomy of those special parts. I had taken my course of study as a dental student with the medical men in the early days, and I knew how little they had been given in that particular department. Upon that basis I was able to build something that was tangible and constructive. We passed from our study of anatomy and histology to the broader aspects of the diseases of the mouth, and then were able to review the pathologies with which we are more or less familiar. Then, having given a course of lectures to the medical students in the third year, finally in their fourth year, when almost ready to be graduated, I began to show them the practical relations, the various applications, and the approved methods, of diagnosis and treatment and the correlated elements which a physician should appreciate in his relation with dentists. In order to complete this instruction, I would take these men in groups to the Massachusetts General Hospital, where I am on the staff in the Department of Rhinology and Laryngology, and there show the students in the clinic not one case, but twenty-five cases in a morning comprising diseases of the antrum, enlarged glands, infected tonsils, deviated septa, involvements of the sinuses, malformations, cases of neuralgias quite obscure, and our methods of approaching the problem for its ultimate solution, requiring that these medical men take notes. They became so interested that they asked questions, and 
fell back upon the foundation which I had already laid for an understanding in dealing with those cases, any and every one of which might at some time enter their offices with the particular problem involved.

Having made the diagnosis, the next step was the question of treatment. These men would come later and see what we would do in the way of treatment. Occasionally a patient would be referred to the neurological clinic or to the general medical clinic for further examination or for X-raying, as the case might demand.

The next step was a study of an operation in oral surgery. The men would see the operation, learn the why and wherefore for it, have an opportunity to study the technic, and then, as the next step, would see the patient perhaps after one week's treatment, and finally the completed case, if it happened to be something outside the ordinary routine case.

In this way we are able to correlate cause and effect. The students are able to get our definite point of view, which is of great value to these men, and they have said to me frequently: "This is the first case in the whole medical course in which we have been able to follow the problem from the beginning to the end and see the results that have been obtained." Of course, I could only touch in superficial manner on the questions of Orthodontia, but these men invariably go back to the dental school clinic at some later time to see what is done with particular cases of deformity; and have opportunity to see before the end of the year what beautiful work is being done in regulating. Furthermore they are able to realize that probably sixty-five per cent of the antrial cases are associated with diseased teeth, and that no amount of operating on the antrum from a laryngological point of view is sufficient to clean up the disease without the concomitant cooperation of the dentist. This interrelated study with medical students who learn the dental viewpoint, has proved immense value as these men after graduating soon learn to cooperate with their local dentists in their attempts to solve many problems.

Dr. Thornton: You know how the very nature of a micro-organism changes if you change the medium of development. My medium of development was changed six years ago, when I was, (happily for the patients), lifted out of the sphere of general practice, since which event I have been devoting my time to hospital work.

As I have seen the close relationship existing between mouth conditions and the general health of the body in various pathological conditions, I have come to realize this fact: That in future there must be a closer cooperation and appreciation between the men who practice dentistry and the men who practice medicine. Neither can get along without the other, and we must rise to the situation. 